\title{
ANTHELMINTIC RESISTANCE AND ASSOCIATED MANAGEMENT PRACTICES IN LOCAL HORSES IN SOKOTO METROPOLIS, NIGERIA
}

\author{
Abubakar Musa Mayaki ${ }^{1}$, Fatimah Folashade Mohammed ${ }^{1}$, Sherifat Banke Idris ${ }^{2}$ \\ ${ }^{1}$ Department of Veterinary Medicine, Faculty of Veterinary Medicine, \\ Usmanu Danfodiyo University, Sokoto, Nigeria \\ ${ }^{2}$ Department of Veterinary Pharmacology and Toxicology, Faculty of Veterinary \\ Medicine, Usmanu Danfodiyo University, Sokoto, Nigeria
}

Received 30 March 2017; Received in revised form 21 September 2017; Accepted 15 November 2017

\begin{abstract}
This study was carried out to assess the management practices used in the control of gastrointestinal (GI) nematodes of horses and to determine the efficacy of three anthelmintics commonly used in Sokoto metropolis. A questionnaire was administered on management practices, while an anthelmintic efficacy test was carried out using 15 horses. The 15 horses were divided into three groups (A, B and C) comprising of 5 each and treated with albendazole, ivermectin and fenbendazole, respectively. The faecal egg count reduction test (FECRT) was used to determine the efficacy and faecal culture was used to determine the parasite species. Majority of the respondents (80\%) claimed to have worm control strategies, but only $32.5 \%$ used anthelmintics for the control of GI parasites. $62.5 \%$ of respondents designed their deworming plan, while only $25 \%$ relied on veterinarians. Most of the treatments were done by the horse owners and/or handlers and they largely depended on visual judgement in dosage determination. Their selection of anthelmintics was based on familiarity and $52.5 \%$ of the respondents dewormed their horses six times a year using a particular class of anthelmintic or herbal remedies. Resistance against albendazole as well as suspected resistance against fenbendazole by the GI nematodes identified was observed, while ivermectin demonstrated high efficacy against all nematodes isolated. In conclusion, a single dose of subcutaneous injection of ivermectin was highly effective against gastrointestinal parasites in horses, while the worm control strategies employed by respondents enhanced the selection of nematode resistance to albendazole and fenbendazole.
\end{abstract}

Key words: anthelmintic efficacy, horses, gastrointestinal parasites, Sokoto

\section{INTRODUCTION}

Horses have played a very important role in the northern part of Nigeria. Majority of the horses are local breeds, kept under traditional husbandry practices and depend mostly on grasses, hay and grains as feed sources with minimum health care interventions (1). Of all the infectious diseases, parasitic diseases are the major obstacle in the growth and development of animal health all over

Corresponding author: Dr Abubakar Musa Mayaki

E-mail address: bubakar241@yahoo.com

Present address: Department of Veterinary Medicine, Faculty of Veterinary

Medicine, Usmanu Danfodiyo University, Sokoto, Nigeria

Phone: +2348035233598

Copyright: (C) 2017 Mayaki A.M. This is an open-access article published under the terms of the Creative Commons Attribution License which permits unrestricted use, distribution, and reproduction in any medium, provided the original author and source are credited.

Competing Interests: The authors have declared that no competing interests exist.

Available Online First: 14 December 2017

Published on: 15 March 2018

https://doi.org/10.1515/macvetrev-2017-0031 the world (2). It is also one of the most important problems for equids in developing countries. Several nematode species infest horses and other equids, but the prevalence of other species is usually lower than that of strongyles, particularly cyathostomins $(3,4)$.

The control strategy for parasitic nematodes has mostly relied on the use of anthelmintics or the combination of anthelmintics and pasture management, although studies have demonstrated the presence of nematodes resistant to one or more anthelmintics in different regions of the world (5-9). The development of resistance among nematodes has largely been attributed to their considerable population sizes, high levels of genetic diversity, relatively rapid generation rates and common practice of interval-based treatment programmes $(10,11)$.

High prevalence of gastrointestinal (GI) nematodes, particularly strongyle infestations in equids through coprological analysis have consistently been reported in Nigeria (12-15), and reports on 
resistance to anthelmintics in ruminants in Nigeria have been documented (16). However, the status of anthelmintic resistance in horses is not known. In addition, there are no published studies describing the factors that affect the prevalence of the various parasitic nematode species, and the development and spread of anthelmintic resistance in horses to the best of our knowledge. In order to address this lack of information, this study was conducted to assess the management practices used in the control of helminth infestation and to determine the efficacy of anthelmintics commonly used in Sokoto metropolis to control GI nematodes of horses.

\section{MATERIAL AND METHODS}

\section{Study area}

The study was conducted in Sokoto State, Nigeria. Geographically, Sokoto is located in the north-western part of Nigeria, between $4^{0} 8^{\prime}$ to $6^{0} 54^{\prime} \mathrm{E}$ and $12^{0}$ to $13^{0} 58^{\prime} \mathrm{N}$. It has an estimated population of 3.7 million people whose main occupations are farming, animal husbandry and fishing (17). It is the second largest State in Nigeria, the livestock population is estimated to be about 1.18 million cattle, 2.90 million goats, 1.98 million sheep, 2.0 million chickens, 45000 camels, 34532 horses and 51388 donkeys (18).

\section{Questionnaire survey}

Questionnaires aimed at determining the management practices used in the control of helminth infestation in horses were administered to horse owners/handlers within Sokoto metropolis. Components of the questionnaire include: demographic information, worm control strategies, utilization of anthelmintics and stable management practices. The questionnaire comprised of 21 questions: 5 open- and 16 close-ended multiplechoice questions with the opportunity to include additional comments at the end of each question.

\section{Study animals and management}

The study animals comprised of Nigerian local horses kept in 40 stables or farms. Each stable or farm has an average herd size of horses ranging from two to twenty, comprising mainly of males (colt or stallion). The management system of most of the stables was based on traditional practices with the horses kept tethered on an open field, using sand as bedding with or without provision for housing. They were kept purposely either for racing, traditional purpose (durbar), companion and/or polo and each horse has its own watering and feeding trough. They were fed with millet, wheat bran, hay and crop residues.

\section{Study design and faecal egg counts}

The study was conducted under strict adherence to the principles of care and use of farm animals in research, teaching and testing (19). A preliminary faecal screening test was performed on 100 faecal samples collected per rectum using clean gloves. The samples were positive for Strongyle eggs, with eggs per gramme (EPG) ranging from 50 to 3475 . Horses with greater than 200 EPG of faeces that had not received any anthelmintic agent in the last three months were considered for the anthelmintic efficacy test. A total of 15 horses were selected from three stables (A, B, C) with similar management practices, five horses per group (stable). The criteria for group formation were the owner's acceptance of the study, as well as the actual possibility of faecal sampling, both for pre-treatment and post-treatment. The management practices (as identified in the questionnaire) considered were types of feed, mode of feeding (in container on the ground), weekly feeder cleaning and daily stable/manure cleaning. Information about the individual horse such as name, age, identification marks was recorded. Each group was then randomly assigned to an anthelmintic agent with albendazole administered to horses in group A, ivermectin administered to horses in group B and fenbendazole administered to horses in group C. The approximated weight (W) of each horse was estimated from body measurement data (20). The treatments were given based on registered label dose rate recommended by the manufacturers (Table 1).

Table 1. Description of the anthelmintic drugs used in the FECRT for efficacy evaluation

\begin{tabular}{lllllll}
\hline Trade name & Composition & $\begin{array}{l}\text { Dosage } \\
\mathbf{m g} / \mathbf{k g}\end{array}$ & Route & Batch No & Manufacture Date & Expiry Date \\
\hline A-zole ${ }^{\circledR}$ & Albendazole 2.5\% & 5.0 & Orally & EAZ1520 & $06 / 2015$ & $05 / 2018$ \\
Herbeiivermec ${ }^{\circledR}$ & Ivermectin 1\% & 0.2 & Subcut & 160512 & $05 / 2016$ & $05 / 2019$ \\
Fenbzole ${ }^{\circledR}$ & Fenbendazole 2.5\% & 7.5 & Orally & LP16002 & $01 / 2016$ & $12 / 2018$ \\
\hline
\end{tabular}




\section{Sample collection and faecal analysis}

Faecal samples were collected rectally, before the anthelmintic treatment on day 0 and day 14 post-treatment, to determine the faecal egg counts (FEC). The samples were either immediately processed or stored at $4^{\circ} \mathrm{C}$ for 24 hours before processing. Simple flotation technique was used to demonstrate the presence of helminth eggs and the EPG of faeces were determined using a modified McMaster method with a sensitivity of 25 EPG by dissolving 4 grammes of faeces in $26 \mathrm{ml}$ flotation fluid for each sample (21). Pooled faecal cultures for each treatment group were done based on $5 \mathrm{~g}$ of faeces collected from each animal in a group before treatment (day 0) and on day 14 after treatment. The faecal samples were incubated at room temperature (approximately 28 to $30^{\circ} \mathrm{C}$ ) for 12 days, regularly aerated and checked for desiccation, and moistened when necessary. The larvae were recovered by baermannization, quantified and identified as described by MAFF (21). The identification was done using the number, shape and arrangement of intestinal cells (22).

\section{Anthelmintic efficacy test}

The resistance to anthelmintic drugs was determined using the Faecal Egg Count Reduction Test (FECRT) (23). The arithmetic mean and prevalence of pre-treatment (Pre) and posttreatment (Post) helminth parasitism was calculated based on EPG. The efficacy of the anthelmintic treatment was calculated using the pre-treatment and post-treatment results obtained, according to the following equation:

$$
\mathrm{FECR}=100 \times[(1-\text { FEC Post }) /(\text { FEC Pre })]
$$

The 95\% confidence interval (CI 95\%), as well as the lower confidence level (LCL) was determined. The results obtained using FECRT was interpreted based on the faecal egg reduction percentage, as well as on the lower limit of the 95\% confidence interval (LCL 95\%). In accordance with the methods recommended by the World Association for the Advancement of Veterinary Parasitology for the detection of anthelmintic resistance in horses and ruminants (23).

i. resistance is present (R) if FECR $<90 \%$ and the LCL $95 \%<90 \%$

ii. resistance is suspected (S) if FECR $\geq 90 \%$ and/ or $\mathrm{LCL} 95 \%<90 \%$

iii. no resistance $(\mathrm{N})$ if FECR $\geq 90 \%$ and $\mathrm{LCL}$ $95 \%>90 \%$

\section{Statistical analysis}

The data generated from the questionnaire was entered into Microsoft Excel and analyzed using descriptive statistics (percentages and tabulations). The software used was SPSS for Windows, version 14.0. The efficacy of anthelmintics was evaluated based on the reduction in faecal egg counts. Calculations of the arithmetic means, percentage of reduction between pre- and post-treatment faecal nematode egg outputs and 95\% upper and lower confidence limits for the reduction were conducted according to the method described by Coles et al. (23).

Table 2. Worm control strategies employed for the control of gastrointestinal nematodes in horses within Sokoto metropolis, Nigeria (total of analysed questionnaires $n=40$ )

\begin{tabular}{lcc}
\hline Description & No. respondents & Response rate (\%) \\
\hline Parasitic control method & 13 & 32.5 \\
Anthelmintics & 5 & 12.5 \\
Herbal & 22 & 55.0 \\
Both method & & \\
\hline Presence of deworming plan & 32 & 80.0 \\
Yes & 8 & 20.0 \\
No & & \\
\hline Designing of deworming plan & 25 & 62.5 \\
Horse owner/handler & 10 & 25.0 \\
Veterinarian & 5 & 12.5 \\
Don't have & & \\
\hline Basis for deworming & 0 & 0.0 \\
FEC & 22 & 55.0 \\
Clinical sign & 18 & 45.0 \\
Anytime & & \\
\hline
\end{tabular}




\section{RESULTS}

Questionnaire survey on management practices

A total of 40 responses were analyzed. All the respondents were male and their age ranged between 13 and 55 years, with 12 (30\%) being young adult ( $<20$ years), 19 (47.5\%) adult (21-40 years) and 9 (22.5\%) were ( $>40$ years) old. Based on the primary occupation, respondents were horse handlers (47.5\%), civil servants (20\%) and 32.5\% traders. Sixty percent of the respondents had secondary school certificates, $15 \%$ were degree holders, $10 \%$ had primary school certificates and $15 \%$ had no formal education.

Eighty percent of the respondents claimed to have a deworming plan, however, only $32.5 \%$ used anthelmintics, while 55\% combined the use of anthelmintics and herbal medicines in their worm control strategies (Table 2). According to $62.5 \%$ of respondents, designing of the deworming plan was done by the horse owners/handlers, while only $25 \%$ relied on veterinarians. Most of the respondents identified helminth infestation by signs of a rough coat, weight loss and presence of worms in faeces.

Table 3. showed the utilization of anthelmintics for the control of gastrointestinal parasites in horses in the study area, with albendazole (80\%) being the most commonly used anthelmintic. The common herb used is neem (Azadirachta indica) leaves and stem. The neem leaves and/or stem are usually either soaked in water over night or boiled and about 1 to 2 litres/horse of the extract is administered orally. Ninety percent of respondents

Table 3. Utilization of anthelmintics for the control of gastrointestinal parasites in horses within Sokoto metropolis, Nigeria (total of analysed questionnaires $n=40$ )

\begin{tabular}{|c|c|c|}
\hline Description & No. of answers & Proportion of answers (\%) \\
\hline \multicolumn{3}{|l|}{ Dewormer administration } \\
\hline Horse owner & 30 & 75.0 \\
\hline Horse handler & 5 & 12.5 \\
\hline Paravet & 1 & 2.5 \\
\hline Veterinarian & 4 & 10.0 \\
\hline \multicolumn{3}{|l|}{ Dosage determination } \\
\hline Visual judgement & 36 & 90.0 \\
\hline Weight of individual horse & 4 & 10.0 \\
\hline \multicolumn{3}{|l|}{ Weight estimation } \\
\hline Visual estimation & 38 & 95.0 \\
\hline Weight bands & 1 & 2.5 \\
\hline Body measurements & 1 & 2.5 \\
\hline \multicolumn{3}{|l|}{ Selection of anthelmintics } \\
\hline Familiarity & 34 & 85.0 \\
\hline Low price & 1 & 2.5 \\
\hline Horse handler recommendation & 1 & 2.5 \\
\hline Vet recommendation & 4 & 10.0 \\
\hline \multicolumn{3}{|l|}{ Formulation of dewormer } \\
\hline Drench & 35 & 87.5 \\
\hline Paste & 2 & 5.0 \\
\hline Drench \& paste & 2 & 5.0 \\
\hline Drench \& Injectable & 1 & 2.5 \\
\hline \multicolumn{3}{|l|}{ Frequency of deworming } \\
\hline Once a year & 1 & 2.5 \\
\hline Twice a year & 4 & 10.0 \\
\hline Thrice a year & 4 & 10.0 \\
\hline Four times a year & 7 & 17.5 \\
\hline Six times a year & 21 & 52.5 \\
\hline None & 3 & 7.5 \\
\hline \multicolumn{3}{|c|}{ Alternate use of anthelmintic classes } \\
\hline I do change & 10 & 25.0 \\
\hline Change occasionally & 9 & 22.5 \\
\hline I don't change & 21 & 52.5 \\
\hline
\end{tabular}


Table 4. Stable management practices employed for the control of gastrointestinal parasites in horses within Sokoto metropolis, Nigeria (total of analysed questionnaires $n=40$ )

\begin{tabular}{|c|c|c|}
\hline Description & No. of stables & $\%$ of stables \\
\hline \multicolumn{3}{|l|}{ Type of feed } \\
\hline Grains \& hay & 7 & 17.5 \\
\hline Grains \& grasses & 3 & 7.5 \\
\hline Grains, hay\& grasses & 30 & 75.0 \\
\hline \multicolumn{3}{|l|}{ Mode of feeding } \\
\hline Feed on ground & 10 & 25.0 \\
\hline In container on the ground & 25 & 62.5 \\
\hline In a raised container & 5 & 12.5 \\
\hline \multicolumn{3}{|l|}{ Feeders cleaning } \\
\hline Don't clean & 9 & 22.5 \\
\hline Daily\&before every feed & 16 & 40.0 \\
\hline Weekly & 10 & 25.0 \\
\hline Anytime & 5 & 12.5 \\
\hline \multicolumn{3}{|l|}{ Cleaning drinkers } \\
\hline Daily & 28 & 70.0 \\
\hline Weekly & 2 & 5.0 \\
\hline Anytime & 9 & 22.5 \\
\hline Don't clean & 1 & 2.5 \\
\hline \multicolumn{3}{|l|}{ Stable/manure cleaning } \\
\hline Daily & 19 & 47.5 \\
\hline Weekly & 1 & 2.5 \\
\hline Anytime & 20 & 50.0 \\
\hline \multicolumn{3}{|l|}{ Use of bedding } \\
\hline Yes & 15 & 35.0 \\
\hline No & 25 & 62.5 \\
\hline
\end{tabular}

use visual judgement in dosage determination in case of anthelmintic. Seventy five percent of the respondents, who are horse owners and $12.5 \%$ who are horse handlers administer the anthelmintics by themselves. According to $85 \%$ of the respondents, anthelmintics selection is based on familiarity and is usually in drench form. Fifty two point five percent of the respondents deworm their horses six times a year using either anthelmintic or herb, but they do not change the class of the anthelmintics used in their stables. Furthermore, they had no schedule on the choice of the type of dewormer (chemical anthelmintic or herb) to be used at any deworming period.

Based on the stable management practices employed (Table 4), daily cleaning of stables or

Table 5. Faecal egg count reduction test in horses naturally infected with gastrointestinal nematodes from 3 stables within Sokoto metropolis, Nigeria

\begin{tabular}{llll}
\hline Treatment groups & $\mathbf{A}(\mathbf{n}=\mathbf{5})$ & $\mathbf{B}(\mathbf{n}=\mathbf{5})$ & $\mathbf{C}(\mathbf{n}=\mathbf{5})$ \\
\hline Pre-treatment mean EPG & 1850 & 1750 & 1300 \\
Post-treatment mean EPG & 700 & 0 & 100 \\
FECR (\%) & 62.2 & 100.0 & 92.3 \\
Upper 95\% Cl (\%) & 78.0 & - & 98.0 \\
Lower 95\% Cl (\%) & 36.0 & - & 72.0 \\
\hline Interpretation & Resistant & No resistance & Resistance suspected
\end{tabular}

Group A = Albendazole; Group B = Ivermectin; Group C = Fenbendazole; Mean EPG = arithmetic mean of faecal nematode egg counts; FECR $=$ faecal egg count reduction 
Table 6. Infective larva (L3) from faecal cultures from the horses before and after treatment

\begin{tabular}{lcccccc}
\hline \multirow{2}{*}{ Infective larva (L3) } & \multicolumn{2}{c}{ A } & \multicolumn{2}{c}{ B } & \multicolumn{2}{c}{ C } \\
\cline { 2 - 7 } & Pre-treat & Post-treat & Pre-treat & Post-treat & Pre-treat & Post-treat \\
\hline Strongylus vulgaris & Yes & Yes & Yes & No & Yes & Yes \\
Strongylus edentatus & No & No & Yes & No & No & No \\
Strongylus equinus & Yes & Yes & No & No & Yes & Yes \\
Cyathostomum spp type $\boldsymbol{A}$ & Yes & No & Yes & No & No & No \\
Cyathostomum spp type $\boldsymbol{C}$ & Yes & Yes & Yes & No & Yes & Yes \\
Cyathostomum spp type $\boldsymbol{D}$ & No & No & Yes & No & No & No \\
Cyathostomum spp type $\boldsymbol{G}$ & Yes & Yes & No & No & Yes & Yes \\
Gyalocephalus capitatus & Yes & No & No & No & No & No \\
Trichostrongylus axei & Yes & No & No & No & Yes & No \\
\hline
\end{tabular}

Group A = Albendazole; Group B = Ivermectin; Group C = Fenbendazole

manure was not regular. Daily cleaning of the feeding and watering container was practiced by $40 \%$ and $70 \%$ of the stables respectively. The use of sand bedding is a common practice among $62.5 \%$ of the stables.

Anthelmintic efficacy test and larval identification

The result of faecal egg count reduction tests (FECRT) is shown in Table 5. Nematode infective larvae (L3) recovered in pre- and post-treatment pooled faecal cultures of all treatment groups during the FECRT are presented in Table 6. The majority $(90.26 \%)$ of the larvae in the culture were Cyathostomum spp. The mean percentages of other infective larvae identified were Strongylus vulgaris (2.96\%), S. edentatus (2.02\%), S. equinus (3.19\%), Trichostrongylus axei (4.37\%) and Gyalocephalus capitatus (3.20\%). Albendazole and fenbendazole were unable to kill most of the large and small strongyles identified, while they were all susceptible to ivermectin.

\section{DISCUSSION}

The need to minimize parasitic diseases, as well as to address the threat of wide spread anthelmintic resistance in equine nematodes necessitates a change in the approach to control parasitic infestation in order to preserve anthelmintic efficacy. This study therefore provides information on the management practices employed and about the efficacy of albendazole, fenbendazole and ivermectin on GI nematodes of horses within Sokoto metropolis.

The use of anthelmintics and herbal remedies were the main parasitic control method employed in the study area. Although the efficacy of some of these herbal remedies against ruminant nematodes has been tested in vivo and in vitro $(24,25)$, their efficacy in horses has not been published from the study area to the best of our knowledge. The effectiveness of neem against parasites was attributed to the compound called azadirachtin. Azadirachtin interferes with the central nervous system of parasites via inhibition of excitatory cholinergic transmission and partly blocks the calcium channel resulting in expulsion of parasites from the body of hosts $(26,27)$. This is the same mechanism employed by some of the anthelmintics used. A higher percentage of the respondents had a deworming plan, however, only $25 \%$ relied on veterinarians in designing the plan. This could be the reason why most deworming is done at any convenient time of the year or following manifestation of clinical signs as indicated by a larger percentage of respondents. Despite the presence of anthelmintic resistant nematodes for several decades, and the importance of faecal egg count in the targeted dosing method of helminth control, there has been concern regarding poor dissemination of this information among equine veterinarians and horse owners (28). Low level of veterinary involvement in parasite control plan was also reported in a majority of racing yards in the UK (29). This finding possibly contributed to the non-implementation of FECs, which was evident in this present study, with no single respondent using FEC test in designing their worm control strategies. More so, neither systematic drenching nor FECbased drenching systems was practiced by any of the respondents. One can therefore imply the already described reluctance of ruminant breeders to implement selective drenching $(30,31)$ to apply for horse owners too. It is therefore important for 
veterinarians to provide more integrated parasite control advice to the horse owners and handlers.

The respondents based selection of anthelmintics on familiarity with the drug and majority of them gave a particular type or class of anthelmintic. The administration of the dewormer, which was usually based on visual weight estimation, was largely performed by the horse owners and handlers. This is in accordance with previous studies which showed that objective weight estimation was underutilized, with 87 to $94 \%$ of the owners relying on visual estimation of weight alone $(8,32)$. The practices of self-treatment of horses by the horse owners and/or handlers may be the reason for their selection and buying of anthelmintics formulation for oral route administration which is easy to administer. More so, the need to pay an added value to veterinarians may become pointless as the importance given to costs of veterinary care is one of the most important obstacles among pet owners to veterinary visits (33). This practice could obviously lead to treatment failure as a result of inappropriate dosing due to underestimation of the live weight. Also, considering the frequency of deworming per year with a particular anthelmintic type and wrong dosing, development of resistance to those particular classes of anthelmintics is not very unlikely.

The management practices, particularly the type of feed, mode of feeding and inconsistence in the cleaning of feeder and stable/ manure, employed by most of the respondents may also encourage high load of parasites in the environment as previously reported (34). In addition, studies from different parts of the world and Nigeria in particular have documented helminth diseases as the most prevalent disease in horse population, of which strongyles had the highest prevalence $(2,3,4,13,14,15)$. Previous coprological analysis of horses from Sokoto-Nigeria revealed a prevalence of $84.4 \%$ for helminths, with $75.5 \%$ being strongyles (12). Sixty eight point eight percent prevalence rate for strongyles was reported in Kaduna, Nigeria (35), while Biu et al. (36) reported two major helminths: Parascaris equorum (48.6\%) and Strongyles (42.9\%) in Maiduguri, Nigeria. The percentage prevalence of larvae in the culture are similar with what was reported by previous researchers, particularly with cyathostomins being the most common species in horse population $(4,37,38)$.

The use of herbal remedies (neem) may also contribute to the high burden of the nematodes in the horses examined and possibly encourage resistance to common anthelmintics. This is because most of the respondents had no schedule on which dewormer (anthelmintic or herb) is to be used at any deworming period, effectiveness of the neem extract used is not known, and probably horses may not be receiving required doses. More so, studies have showed varying degree of efficacy of neem leaves on equine helminths. Ali (39) documented 53.6\% reduction against Gastrodiscus spp, while Mahboob et al. (40) reported $6.89 \%$ and $8.62 \%$ reduction on day 7 and 14 post treatment and Yadav (41) reported 21\% reduction for strongyles.

The anthelmintic efficacy screening showed that albendazole and fenbendazole were unable to kill most of the large and small strongyles identified, while their susceptibility to ivermectin was $100 \%$. Although the most pathogenic species of large strongyle ( $S$. vulgaris) was identified, however, no clinical signs due to its infestation were observed in any of the studied animals.

The resistance of most nematodes identified in this study to albendazole and to a lesser extent fenbendazole is a true reflection of what was observed in the questionnaire-based survey, where the choice of anthelmintic selection among horse owners or handlers was largely dependent on familiarity with a particular anthelmintic and practice of using a particular type or class of anthelmintic (benzimidazoles). The low efficacy observed with fenbendazole was a bit higher than what has been reported by in other studies from other parts of the world $(8,42,43,44)$. The resistance of nematodes in horses to albendazole in this study, with an efficacy value of $36 \%$, was very low when compared with previous studies $(7,45)$. Contrary to our findings on the efficacy of ivermectin, some studies reported anthelmintic resistance against macrocyclic lactones, particularly of small strongyle $(46,47$, 48). However, reduction in naturally infected horses observed in this present study confirms that ivermectin has excellent anthelmintic efficacy against many species of GI nematodes of horses as previously reported $(48,49)$. Also considering the management practices (feeding on grains, hay and grasses in containers on the ground, weekly cleaning of feeders and daily clearing of manure) used as inclusion criteria for the selected stable and the EPG recorded pre- and post-treatment, we strongly believe the differences in efficacy observed in this study are due to the anthelmintics used and the stable management has no influence on the outcome of the study. 


\section{CONCLUSION}

To the best of our knowledge, this is the first study of management practices and anthelmintic efficacy in horses conducted in Sokoto, north-western region of Nigeria. The worm control strategies employed by horse owners and/or handlers possibly enhance the selection of nematodes resistant to albendazole and fenbendazole, while a single dose of subcutaneous injection of ivermectin was highly effective against gastrointestinal parasites in horses. The resistances observed were associated with risks of under dosing, continued use of a class of anthelmintic irrespective of its efficacy status, as well as non-use of FECs and veterinary involvement in the control of parasites.

\section{CONFLICT OF INTEREST}

The authors declared that they have no potential conflict of interest with respect to the authorship and/or publication of this article.

\section{ACKNOWLEDGEMENT}

The authors wish to thank Dr. Shehu Sidi and Dr. Abdulrahman Balarabe for helping with horse owner's contact and Prof. A.O. Talabi for his comments and corrections to the manuscript.

\section{REFERENCES}

1. Mayaki, A.M., Ibrahim, J.I. (2015). Prevalence of equine stereotypic behaviour and its associated risk factors in Kano Metropolis, Nigeria. Afr J Livest Ext. 15, 54-60.

2. Mahfooz, A., Masood, M.Z., Yousaf, A., Akhtar, N., Zafar-Pakistan, M.A. (2008). Prevalence and anthelmintic efficacy of Abamectin, against gastrointestinal parasites of horses. Pakistan Vet J. 28(2): 76-78.

3. Relf, V.E., Morgan, E.R., Hodgkinson, J.E., Matthews, J.B. (2013). Helminth excretion with regard to age, gender and management practices on UK Thoroughbred studs. Parasitology 140, 641-652. https://doi.org/10.1017/S0031182012001941 PMid:23351718
4. Morariu, S., Mederle, N., Badea, C., Dărăbuş, G., Ferrari, N., Genchi, C. (2016). The prevalence, abundance and distribution of cyathostomins (small strongyles) in horses from western Romania. Vet Parasitol. 223, 205-209.

https://doi.org/10.1016/j.vetpar.2016.04.021

PMid:27198801

5. Laugier, C., Sevin, C., Ménard, S., Maillard, K. (2012). Prevalence of Parascaris equorum infection in foals on French stud farms and first report of ivermectin-resistant $P$. equorum populations in France. Vet Parasitol. 188, 185-189.

https://doi.org/10.1016/j.vetpar.2012.02.022

PMid:22494940

6. Reinemeyer, C.R. (2012). Anthelmintic resistance in non-strongylid parasites of horses. Vet Parasitol. $185,9-15$.

https://doi.org/10.1016/j.vetpar.2011.10.009

PMid:22078748

7. Traversa, D., Castagna, G., von SamsonHimmelstjerna, G., Meloni, S., Bartolini, R., Geurden, T., Pearce, M.C., Woringer, E., Besognet, B., Milillo, P., D’Espois, M. (2012). Efficacy of major anthelmintics against horse cyathostomins in France. Vet Parasitol. 188, 294-300.

https://doi.org/10.1016/j.vetpar.2012.03.048

PMid:22538094

8. von Samson-Himmelstjerna, G. (2012). Anthelmintic resistance in equine parasites: detection, potential clinical relevance and implications for control. Vet Parasitol. 185, 2-8.

https://doi.org/10.1016/j.vetpar.2011.10.010

PMid:22100141

9. Peregrine, A.S., Molento, M.B., Kaplan, R.M., Nielsen, M.K. (2014). Anthelmintic resistance in important parasites of horses: does it really matter? Vet Parasitol. 201, 1-8.

https://doi.org/10.1016/j.vetpar.2014.01.004

10. Gilleard, J.S., Beech, R.N. (2007). Population genetics of anthelmintic resistance in parasitic nematodes. Parasitology134, 1133-1147. https://doi.org/10.1017/S0031182007000066 PMid:17608973

11. Kaplan, R.M., Nielsen, M.K. (2010). An evidencebased approach to equine parasite control: it ain't the 60s anymore. Equine Vet Educ. 22, 306-16. https://doi.org/10.1111/j.2042-3292.2010.00084.x

12. Alayande, M.O., Onakpa, M.M., Lawal, M.D. (2003). Prevalence of helminth parasites in horses in Sokoto. Nig J Parasitol. 24, 191-193. 
13. Useh, N.M., Oladele, S.B., Ibrahim, N.D., Nok, A.J., Esievo, K.A. (2005). Prevalence of equine diseases in the northern Guinea Savannah of Zaria, Nigeria. J Equine Sci. 16(1): 27-28.

https://doi.org/10.1294/jes.16.27

14. Wosu, M., Udobi, S.O. (2014). Prevalence of gastrointestinal helminths of horses (Equuscaballus) in the southern Guinea Savannah Zone of Northern, Nigeria. J Vet Adv. 4(4): 499-502.

15. Sugun, M.Y., Bresibe, F., Mailafiya, S., Muhammad, M., Suleiman, I., Abechi, A.S. (2015). Prevalence of gastro-intestinal parasite in Donkeys in and around Maiduguri metropolis, Borno state, Nigeria. Direct Res J Agric Food Sci. 3(4): 70-73.

16. Fashanu, S.O., Fagbemi, B.O. (2003). A preliminary investigation of resistance to anthelmintics in strongyles of cattle in Shaki, Nigeria. Afr J Biomed Res. 6, $111-112$.

17. Wikipedia. (2015). [Internet]. https://en.m.wikipidia. org/wiki/sokoto_state

18. FAOSTAT (2013). FAO statistic databases. [Internet]. Food and agriculture organization of the united nations, rome. Italy. www.faostat.fao.org/ site/573/default.aspx

19. Canadian Council on Animal Care Guide (CCAC) (1993). http://www.ccac.ca/Documents/Standards/ Guidelines/Experimental_Animals_Vol1.pdf, retrieved 04/1/2016.

20. Santos, R.F. (1981). Estimation of genetic and phenotypic parameters of the body of horses. The Cava of Brazilian saddle and other Equidae. (pp. 288). Botucatu, Publisher.

21. MAFF. (1986). Ministry of Agriculture, Fisheries and Food. Manual of Veterinary parasitological laboratory techniques. (pp. 160). 3rd ed. Ref. Book 418, H.M.S.O. London, UK.

22. Cernea, M., Madeira de Carvalho, L.M., V. Cozma. (2008). Identification of third stage strongyle larvae (L3). In: Atlas of Diagnosis of Equine Strongylidosis. (pp. 128). Editura Academic Pres.

23. Coles, G.C., Bauer, C., Borgsteede, F.H., Geerts, S., Klei, T.R., Taylor, M.A., Waller, P.J. (1992). World Association for the Advancement of Veterinary Parasitology (W.A.A.V.P.) methods for the detection of anthelmintic resistance in nematodes of veterinary importance. Vet Parasitol. 44, 35-44. https://doi.org/10.1016/0304-4017(92)90141-U

24. Agaie, B.M., Onyeyili, P.A. (2007). Anthelmintic activity of the crude aqueous leaf extracts of Anogeissus leiocarpus in sheep. Afr J Biotechnol. 6(13): 1511-1515.
25. Suleiman, M.M., Mamman, M., Sidiama, A., Ighoja, E.J., Tauheed, M.,Talba, A.M. (2014). Evaluation of anthelmintic activity of Nigerian ethnoveterinary plants; Cassia occidentalis and Guiera senegalensi. Veterinary World 7(7): 536-541.

https://doi.org/10.14202/vetworld.2014.536-541

26. Veerakumari, L., Priya, P. (2006). In vitro effect of Azadirachtin on the motility and acetycholinestrease activity of Cotylophoron cotyphorum (Fischoeder, 1901). J Vet Parasitol, 20, 1-5.

27. Qiao, J., Zou, X., Lai, D., Yan, Y., Wang, Q., Li, W., Deng, S., Xu, H., Gu, H. (2013). Azadirachtin blocks the calcium channel and modulates the cholinergic miniature synaptic current in the central nervous system of Drosophila. Pest. Manag. Sci. 70(7): 10411047.

https://doi.org/10.1002/ps.3644

PMid:24002996

28. Kaplan, R.M. (2002). Anthelmintic resistance in nematodes of horses. Vet Res. 33, 491-507. https://doi.org/10.1051/vetres:2002035 PMid:12387486

29. Relf, V.E., Morgan, E.R., Hodgkinson, J.E., Matthews, J.B. (2012). A questionnaire study on parasite control practices on UK breeding Thoroughbred studs. Equine Vet J. 44, 466-471. https://doi.org/10.1111/j.2042-3306.2011.00493.x PMid:22050130

30. Cabaret, J., Benoit, M., Laignel, G., Nicourt, C. (2009). Current management of farms and internal parasites by conventional and organic meat sheep French farmers and acceptance of targeted selective treatments. Vet Parasitol. 164, 21-29.

https://doi.org/10.1016/j.vetpar.2009.04.018 PMid:19414221

31. Kenyon, F., Jackson, F. (2012). Targeted flock/herd and individual ruminant treatment approaches. Vet Parasitol. 186 (1-2): 10-17. https://doi.org/10.1016/j.vetpar.2011.11.041 PMid:22188982

32. Fritzen, B., Rohn, K., Schnieder, T., von SamsonHimmelstjerna, G. (2010). Endoparasite control management on horse farms - lessons from worm prevalence and questionnaire data. Equine Vet J. 42, $79-83$.

https://doi.org/10.2746/042516409X471485 PMid:20121919

33. Volk, J.O., Felsted, K.E., Thomas, J.G., Siren, C.W. (2011). Executive summary of the Bayer veterinary care usage study. J Am Vet Med Assoc. 238(10): $1275-1282$

https://doi.org/10.2460/javma.238.10.1275

PMid:21568772 
34. Chapman, M.R., French, D.D., Klei, T.R. (2002). Gastrointestinal helminths of ponies in Lousiana: a comparison of species currently prevalent with those present 20 years ago. J Parasitol. 88(6): 1130-1134. https://doi.org/10.1645/0022-3395(2002)088[1130: GHOPIL]2.0.CO;2

35. Umar, Y.A., Maikaje, D.B., Garba, U.M., Alhassan, M.A.F. (2013). Prevalence of gastrointestinal parasites of horses used for cadet training in Nigeria. J. Vet. Adv. 3(2): 43-48. https://doi.org/10.5455/jva.20130219032443

36. Biu, A.A., Olatunde, K.T., Konto, M., Paul, B.T., Ya'uba, A.M. (2012). Prevalence and quantitative faecal analysis of equine Gastrointestinal nematodosis in Maiduguri, Nigeria. Journal Medical and Applied Biosciences 4, 1-6.

37. Kuzmina, T.A., Dzeverin, I., Kharchenko, V.A. (2016). Strongylids in domestic horses: Influence of horse age, breed and deworming programs on the strongyle parasite community. Vet Parasitol. 227, 56-63. https://doi.org/10.1016/j.vetpar.2016.07.024 PMid:27523938

38. Santos, D.W., Dias de Castro, L.L., Giese, E.G., Molento, M.B. (2016). Morphometric study of infective larvae of cyathostomins of horses and their distribution. J Equ Vet Sci. 44, 49-53.

https://doi.org/10.1016/j.jevs.2016.02.237

39. Ali, M. (2005). Prevalence and treatment trials against Gastrodiscus infestation and its effect on various blood components in horses. M.Sc. thesis, (Dep. of Clinical Medicine Surgery), Univ. Vet. Anim. Sci. Lahore, Pakistan.

40. Mahboob, K., Khan, J.A., Khan, M.S. (2008). Prevalence, chemotherapy and haematology of strongylosis in horses of district layyah. J. Anim. Plant. Sci., 18(4): 117-119.

41. Yadav, K. (2013). Efficacy of different doses of Neem (Azadirachtaindica) against gastroinstestinal nematodes in horses. M.V.Sc. \& A.H. thesis (Dep. of Veterinary Medicine), Nanaji Deshmukh Veterinary Science University, Jabalpur.

42. Belmonte, C., Fernandes, F., Gaspary, J., Gama, J., Dotto, F., Otto, M.A., Monteiro, S.G. (2009). Antiparasitics in the control of helmintoses in horses kept in a native field in the central region of Rio Grande do Sul, Brazil. Veterinary in Focus 7(1): 46-51.
43. Relf, V.E., Lester, H.E., Morgan, E.R., Hodgkinson, J.E., Mathews, J.B. (2014). Anthelmintic resistance on UK thorough breed stud farms. Int J Parasitol. 44, 507-514.

https://doi.org/10.1016/j.ijpara.2014.03.006

PMid:24746779

44. Stratford, C.H., Lester, H.E., Pickles, K.J., McGorum, B.C., Mathews, J.B. (2014). An investigation of anthelmintic efficacy against strongyles on equine yards in Scotland. Equine Vet J. $46,17-24$.

https://doi.org/10.1111/evj.12079

PMid:23662803

45. Varady, M., Konigova, A., Corba, J. (2000). Benzimidazole resistance in equine cyathostomins in Slovakia. Vet Parasitol. 94, 67-74. https://doi.org/10.1016/S0304-4017(00)00366-6

46. Slocombe, J.O.D., Coté, J.F., Gannes, R.V. (2008). The persistence of benzimidazole-resistant cyathostomes on horse farms in Ontario over 10 years and the effectiveness of ivermectin and moxidectin against these resistant strains. Cannadian Vet J. 49(1): 56-60.

47. Brady, H.A., Nichols, W.T. (2009). Drug resistance in equine parasites: an emerging global problem. J. Equine Vet Sci. 29, 285-295. https://doi.org/10.1016/j.jevs.2009.04.186

48. Traversa, D., von Samson-Himmelstjerna, G., Demeler, J., Milillo, P., Schurmann, S., Barnes, H., Otranto, D., Perrucci, S., di Regalbono, A.F., Beraldo, P., Boeckh, A., Cobb, R. (2009). Anthelmintic resistance in cyathostomin populations from horse yards in Italy, United Kingdom and Germany. Parasite and Vectors2 (Suppl 2) S2. https://doi.org/10.1186/1756-3305-2-S2-S2 PMid:19778463 PMCid:PMC2751838

49. Nielsen, M.K. (2009). Restrictions of anthelmintic usage: perspectives and potential consequences. Parasites and Vectors2 (Suppl 2) S7. https://doi.org/10.1186/1756-3305-2-S2-S7 PMid:19778468 PMCid:PMC2751843 